\title{
Correlation Between GATA-3, Ki67 and p53 Expressions to Histopathology Grading of Breast Cancer in Makassar, Indonesia
}

\author{
Syarif Ibrahim ${ }^{1}$, Rosdiana Natzir ${ }^{2}$, Andi Asadul Islam ${ }^{3}$, Tjakra Manuaba ${ }^{4}$, \\ A. Benyamin Fachruddin ${ }^{5}$, Burhanuddin Bahar ${ }^{6}$, William Hamdani ${ }^{7}$, Husni Cangara ${ }^{8}$, \\ Mochammad Hatta ${ }^{\text {, * }}$ \\ ${ }^{1}$ Department of Surgery, Wahidin Sudirohusodo General Hospital, Makassar, Indonesia \\ ${ }^{2}$ Department of Biochemistry, Faculty of Medicine, Hasanuddin University, Makassar, Indonesia \\ ${ }^{3}$ Department of Surgery, Neuro Surgery Division, Wahidin Sudirohusodo General Hospital/Faculty of Medicine, Hasanuddin University, \\ Makassar, Indonesia \\ ${ }^{4}$ Department of Surgery, Sanglah General Hospital/Faculty of Medicine, Udayana University, Denpasar, Indonesia \\ ${ }^{5}$ Department of Internal Division, Wahidin Sudirohusodo General Hospital/Faculty of medicine, Hasanuddin University, Makassar, Indonesia \\ ${ }^{6}$ Department of Epidemiology Faculty of Public Health, Hasanuddin University, Makassar, Indonesia \\ ${ }^{7}$ Department of Surgery, Wahidin Sudirohusodo General Hospital, Faculty of Medicine, Hasanuddin University, Makassar, Indonesia \\ ${ }^{8}$ Department of Pathology Anatomy, Faculty of Medicine, Hasanuddin University, Makassar, Indonesia \\ ${ }^{9}$ Molecular Biology and Immunology Laboratory, Faculty of Medicine, Hasanuddin University, Makassar, Indonesia
}

\section{Email address:}

syarifibrahim57@gmail.com (S. Ibrahim), Rosdiananatzir@yahoo.com (R. Natzir), Andiasadul@yahoo.com (A. A. Islam), Breastca04@yahoo.com (T. Manuaba), Andifach@yahoo.co.id (A. B. Fachruddin), Ninaisywara14@yahoo.co.id (B. Bahar), Williamhamdani_mks@yahoo.co.id (W.Hamdani), husnicangara@yahoo.com (H. Cangara), Hattaram@indosat.net.id (M. Hatta)

${ }^{*}$ Corresponding author

\section{To cite this article:}

Syarif Ibrahim, Rosdiana Natzir, Andi Asadul Islam, Tjakra Manuaba, A. Benyamin Fachruddin, Burhanuddin Bahar, William Hamdani, Husni Cangara, Mochammad Hatta. Correlation Between GATA-3, Ki67 and p53 Expressions to Histopathology Grading of Breast Cancer in Makassar, Indonesia. Cancer Research Journal. Vol. 4, No. 3, 2016, pp. 43-47. doi: 10.11648/j.crj.20160403.11

Received: February 2, 2016; Accepted: February 24, 2016; Published: April 1, 2016

\begin{abstract}
Background: During the last two decades, research about GATA-3, Ki-67, p53 expressions have been done, but it is still a debate on their use in predicting breast cancer patients' prognosis and survival rate. Expressions of GATA-3 decreased with increasing of histopathology grading of breast cancer and increase with decrease of histopathology grading of breast cancer. The level expression of Ki-67 has a positive relation with breast cancer histopathology grading. p53 has no correlation with high grade differentiation of breast cancer. $\mathrm{p} 53$ is a transcription factor which is activated as a part of cellular stress response that can regulate genes' cellular process, including apoptosis and senescence. Aim: To determine correlation between expressions of GATA 3, Ki-67 and p53 with histopathology grading of breast cancer in Makassar, Indonesia. Methods: Antibody monoclonal GATA 3, Ki-67 and p53 on the nucleus cell were detected with immunohistochemistry method. The positive and negative expressions of GATA 3, Ki67 and p53 were assessed using scoring system according to the proportion of positive cell and coloring intensities. Results: There is no correlation between the higher positive expression ofp53 and higher expression of histopathology grading of breast cancer $(P$ $=0.089)$. While Ki-67 had positive association with higher grade malignancy $(P=0.03)$. However, there was no association between GATA-3 expression and histopathology grading. Conclusion: In our research we found there is no correlation between higher expression of $\mathrm{p} 53$ and low expression of GATA-3 with higher histopathology grading of breast cancer. High expression of Ki-67 have significantly statistic analysis with high expression of histopathology grading of mammary cancer.
\end{abstract}

Keywords: GATA-3, p53 and Ki-67, Histopathology Grading, Breast Cancer 


\section{Introduction}

Breast cancer is a malignancy that occurs in the breast gland. Breast cancer ranks first of the ten types of cancer in women. It was reported incidence of breast cancer in all over the world increase twice, this is the highest level during the late 30 years. WHO predicted the incidence rate of all cancer were 11 millions and every year the amount of breast cancer increase to 7 millions.

In the United States in 2005 reported the incidence of breast cancer by two hundred eleven thousands two hundred fourty $(211,240)$ new cases (ACS, 2006). In 2007 the incidence of breast cancer was reported increase to two hundred fourty three thousands $(243,000)$ with sixty two thousands $(62,000)$ among them with Carcinoma In Situ (CIS). Breast cancer incidence has increased every year. Data from the American Cancer Society in 2010, stated that there are two hundred seven thousands ninety $(207,090)$ new cases of breast cancer in women in the USA with the estimated number of deaths about thirty nine thousands eight hundred fourty $(39,840)$ cases [1]. This figure makes breast cancer as the second most common cause of death in women after lung cancer.

In Indonesia the incidence of breast cancer reported twenty thousands $(20,000)$ new cases/year, around hundred (100) cases among one hundred thousands $(100,000)$ women. 50\% were hospitalized in late stages [2].

In Wahidin Sudirohusodo Hospital in Makassar, Indonesia the incidence of breast cancer in 2007 were 163 new cases and became 189 new cases in 2008. There is increasing cases of late stage of mammary cancer and metastatic stage from $69.9 \%$ in the year 2007 became $74.1 \%$ in the year of 2008 (Wahidin Sudirohusodo Hospital Information System).

$\mathrm{Ki}-67$ expression as detected by immunohistochemistry is one of the most variable indicators of the proliferative status of cancer cells and is referred to as Ki-67. In 2009 at the StGallen breast cancer conference, Ki-67 was recommended as a biomarker for prognosis and sensitivity of cancers to endocrine therapy or chemotherapy [3].

Expression of transcription factor GATA-3 has been shown to be important for normal breast glandular cell development as well for maintaining the differentiated state of cells [4]. Expression of GATA-3 was significantly increased in breast cancer. Decreasing of GATA-3 expressions correlate with increasing tumor histological grade and high patient survival [5].

Expression of p53 in higher differentiated with high proliferation fraction may indicate greater tumor aggressiveness and high risk of relapse [6]. p53 is a critical tumor suppressor that maintains the genetic stability in mammals by having multiple roles in cells cycle arrest, apoptosis, senescence and differentiation. Loss of p53 functions is required for the progression of most cancers. The expression of mutant p53 is correlated with the poor prognosis. The aim of our study was to investigate the expression of $\mathrm{p} 53$, Ki-67 and GATA-3 in correlation with histopathology grading among 50 nested sampling in pathological anatomy laboratory medical faculty in Makassar.

\section{Methods}

A total of 50 cases of breast cancer were studied in laboratory of anatomic pathology Wahidin Sudirohusodo general hospital Faculty of Medicine, Hasanuddin University Makassar, Indonesia The research was performed from October2015 to November 2015 in women from 27 to 73 years old. Fresh tissue from biopsy or tumorectomy was received in department of pathological anatomy and put in buffered formalin solution.

\subsection{Histopathology Grading Characteristic}

The histopathology grade was determined in sections stained with haematoxylin eosin according to the criteria established and histological type according to the WHO classification (1981).

\subsection{Immunohistochemical Study Determination of Expressions of $\mathrm{Ki}-67$ and $\mathrm{p53}$}

Immunohistochemical analyses were determined by the expression levels of $\mathrm{Ki}-67$ and p53. Tissues were fixed in $10 \%$ formaldehyde for 24 hours, routinely embedded in paraffin and cut into $5-\mu \mathrm{m}$ sections. Sections were adherent to APES coated slides and dried at $60^{\circ} \mathrm{C}$ for 2 hours $[7,8]$. Immunohistochemistry was performed according to the manufacturer's instructions, using Streptavidin-Peroxidase (SP-9000) kit, anti Ki-67 (ZM0166), p53 (ZM0408), C-erb2 (ZM0065), all from Zymed laboratories (San Francisco, CA, USA) with antigen retrieval performed according to the manufacturer's instruction. The slides were scored by counting the number of positive cells regardless of the staining intensity versus the total number of cells and calculating the percentage of positive cells (positive cells/total cells in one field), as previously described, the positivity of several fields were averaged and expressed as the ratio of positive cells per field to total cells per field: $<10 \%$, negative, $10 \%-20 \%$ : weakly positive, $26 \%-50 \%$ : positive, $>50 \%$ : strong positive. A cut-off point of $25 \%$ was used to distinguish between the categories of low and high proliferative tumors, a value similar to $20 \%$ or $>20 \%$ [9-11].

\subsection{Immunohistochemistry Staining Procedures of GATA-3}

Tissue in paraffin blocks of size $5-\mu \mathrm{m}$ was cut and glued on the slide poly-L-lysine and then carried. Immunohisto chemical staining was using standard methods Avidin-Biotin peroxidase Complex (ABC). Slide that has not been colored was incubated in $0,1 \%$ trypsin solution in citrate buffer $\mathrm{pH} 6$ for 10 minutes in the microwave with temperature $37^{\circ} \mathrm{C}$. After that examination followed by standard procedure $\mathrm{ABC}$. GATA-3 using GATA-3 monoclonal antibody, at a dilution of 1: 200 [12]. Results were evaluated by immunohistochemical staining using light microscope by 2 pathologists and researchers. The expression of GATA-3 is the accumulation of GATA-3 in the cell nucleus detected by immunohistochemical 
methods. Expression of GATA-3 positive when there is a brown color in the cell nucleus that is seen with a light microscope. This expression is calculated using a scoring system based on the proportion of positive cells and the intensity of the color. Immunoexpression GATA-3 is expressed in a semiquantitative estimation of the scoring system percentage. 0 : No stained cell nucleus, $1: 1-10 \%$ stained, $2: 11-$ 20\%, 3: 21-30\%, 4: 31-40\%, 5: 41-50\%, 6: 51-60\%, 7: 6170\%, 8: 71-80\%, 9: 81-90\%, 10: 91-100\%. Intensity: 1+: weak intensity, 2+: moderate intensity, 3+: strong intensity. Last score obtained by multiplying the intensity of the presentation and the expression of GATA-3 in the cell nucleus to obtain a range of scores 0-30. Then was grouped again to Score 0-3 declared negative, Score 4-30 tested positive [13].

\subsection{Statistical Analysis}

All the data collection were recorded and then analyzed by using software SPSS 17.0 to compare score expressions of GATA-3, p53 and Ki-67 to scores of breast cancer histopathology grading. Statistical analysis was using chisquare test. $P$-value less than 0.05 was considered statistically significant.

\section{Results}

\subsection{GATA-3, p53, Ki-67 Protein Expression Patterns in Breast Tissue}

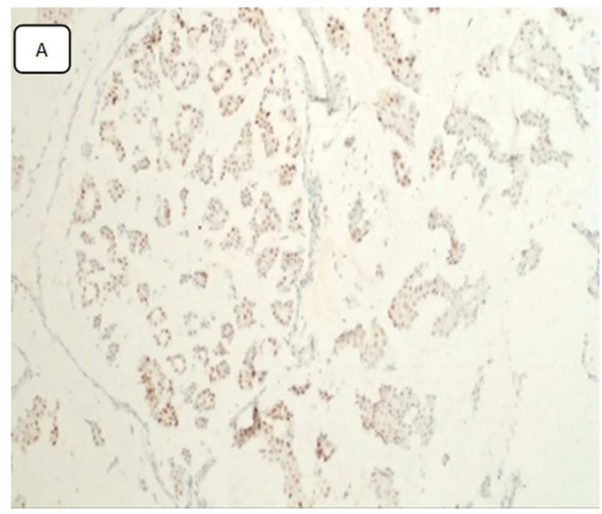

Figure 1. Positive expression of immunohistochemistry of GATA-3 (200x).

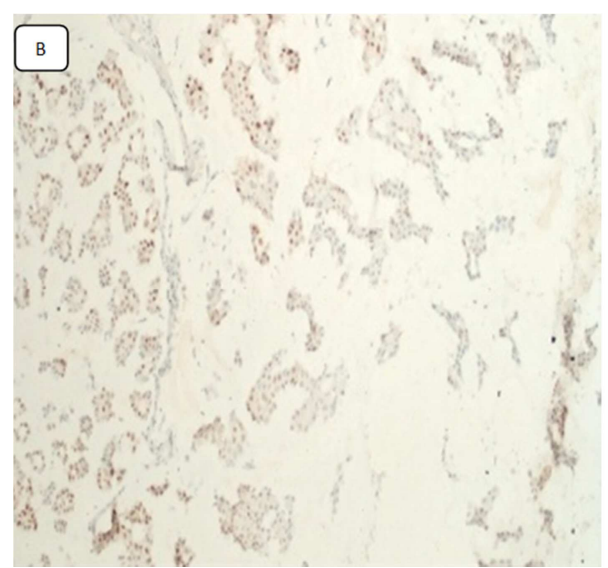

Figure 2. Positive expression of immunohistochemistry of Ki-67 (200x).

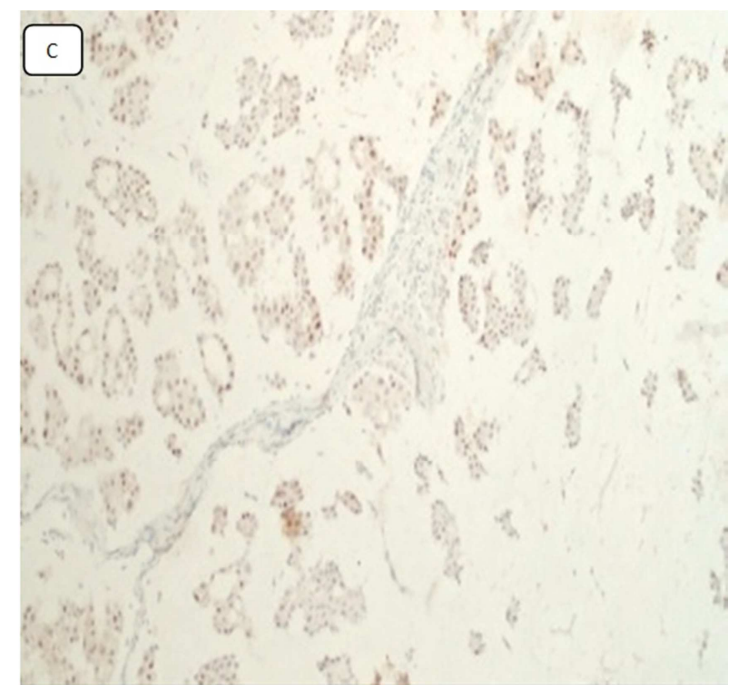

Figure 3. Positive expression of immunohistochemistry of p53 (200x).

Characteristics of Samples, The total sample of 50 studies examined in laboratory of Pathology Anatomy, Faculty of Medicine, Hasanuddin University, Makassar, Indonesia.

Table 1. Characteristic Sampling of the Research

\begin{tabular}{llll}
\hline Characteristics & & Total (N) & Percentage \\
\hline \multirow{2}{*}{ Age } & $=40^{\mathrm{yr}}$ & 12 & $24 \%$ \\
Histopathology & $>40^{\mathrm{yr}}$ & 38 & $76 \%$ \\
Grading & Low Differentiated & 10 & $20 \%$ \\
\multirow{2}{*}{ Protein p53 } & High Differentiated & 40 & $60 \%$ \\
& Negative & 23 & $46 \%$ \\
Protein Ki-67 & Positive & 27 & $54 \%$ \\
& Negative & 17 & $34 \%$ \\
GATA 3 & Positive & 33 & $66 \%$ \\
& Negative & 15 & $30 \%$ \\
\hline
\end{tabular}

In table 1 the sample was mostly from more than 40 year patients with a percentage of $76 \%$ or 38 out of 50 samples. Low differentiated histopathology grading were 20\% (10 cases) while high differentiated were $80 \%$ (40 cases). The amount of p53 protein positive expressions were 54\% (27 cases) where the negative p53 expression levels were $46 \%$ (23 cases).

Ki-67 positive expressions were 66\% (33 cases) and negative expressions were $34 \%$ (17 cases). GATA-3 positive expressions were $70 \%$ (35 cases), where negative expressions were $30 \%$ ( 15 cases).

Table 2. Correlation Between The Expression Of Ki67 and Histopathology Grading of Breast Cancer.

\begin{tabular}{lllll}
\hline & & \multicolumn{2}{l}{ Histopathology Grading } & \multirow{2}{*}{ Total } \\
\cline { 1 - 3 } & Low & High & \\
\hline \multirow{3}{*}{ Ki-67 } & 3 & 27 & 30 \\
& & $6,0 \%$ & $54,0 \%$ & $60,0 \%$ \\
& \multirow{2}{*}{ Nositive } & 7 & 13 & 20 \\
Total & $14,0 \%$ & $26,0 \%$ & $40,0 \%$ \\
& & 10 & 40 & 50 \\
& & $20,0 \%$ & $80,0 \%$ & $100,0 \%$ \\
\hline
\end{tabular}


Correlation between positive expressions Ki-67 with high differentiated histopathology grading were $54 \%$ or 27 cases out of 50 cases. While in low differentiated positive expressions of $\mathrm{Ki}-67$ were found in 3 cases with a percentage of $6 \%$. The negative Ki-67 expressions were found in 13 cases $(26 \%)$ with high differentiated histopathology grading. While negative

Ki-67 expressions were found in 7 cases (14\%) with low differentiated histopathology grading.

Table 3. Correlation Between p53 Expression and Histopathology Grading of Breast Cancer.

\begin{tabular}{lllll}
\hline & & \multicolumn{2}{l}{ Histopathology Grading } & \multirow{2}{*}{ Total } \\
\cline { 1 - 3 } & & Low & High & \\
\hline \multirow{3}{*}{ p53 } & 3 & 24 & 27 \\
& Positive & $6,0 \%$ & $48,0 \%$ & $54,0 \%$ \\
& & 7 & 16 & 23 \\
Total & Negative & $14,0 \%$ & $32,0 \%$ & $46,0 \%$ \\
& & 10 & 40 & 50 \\
& & $20,0 \%$ & $80,0 \%$ & $100,0 \%$ \\
\hline
\end{tabular}

Correlation of positive p53 with high differentiated histopathology grading were 48\% (24 cases) while p53 negative with high differentiated histopathology grading were $32 \%$ (16 cases). A positive p53 expressions were found in 3 cases with low differentiated histopathology grading $(6 \%)$. The percentage of negative p53 expressions with low differentiated histopathology grading is $14 \%$ ( 7 cases).

Table 4. Correlation Between GATA-3 Expression With Histopathology Grading Of Breast Cancer.

\begin{tabular}{lllll}
\hline & & \multicolumn{2}{l}{ Histopathology Grading } & \multirow{2}{*}{ Total } \\
\cline { 1 - 3 } & Low & High & \\
\hline \multirow{3}{*}{ GATA3 } & Positive & 7 & 28 & 35 \\
& & $14,0 \%$ & $56,0 \%$ & $70,0 \%$ \\
& \multirow{2}{*}{ Negative } & 3 & 12 & 15 \\
Total & $6,0 \%$ & $24,0 \%$ & $30,0 \%$ \\
& & 10 & 40 & 50 \\
\hline
\end{tabular}

Positive GATA-3 expressions were seen in high differentiated histopathology grading with a percentage of $56 \%, 28$ among the 50 cases, while GATA-3 negative expressions found in high differentiated histopathology grading with a percentage of $24 \%$ or 12 cases. GATA-3 is only visible negative $6 \%$ (3 cases) in low differentiated histopathology grading. In low differentiated histopathology grading, we found 7 cases with positive GATA3 expressions $(14 \%)$.

\subsection{Statistical Analysis}

In the statistical test using chi-square test, turned out that $\mathrm{P}$ value was less than $0.05(P=0.03)$. This showed that the higher the expression of Ki-67 the higher differentiated result in histopathology grading.

In the statistical test using chi-square test we found that $\mathrm{P}$ was greater than $0.05(P=0.089)$. This shows that the higher expression of p53 was not correlated significantly with the higher histopathology grading in this research.

In the statistical test using chi-square test we found that $\mathrm{P}$ was greater than $0.05(P=0.1$ is not significant). This showed that the low negative expression of GATA-3 was not significantly correlated with higher differentiated histopathology grading in this research.

\section{Discussion}

The mutation of p53 gene is a common phenomenon in numerous human tumors, leading to the accumulation of nonfunctioning p53 protein in the cell nucleus, which can be detected by Immunohistochemistry.

In breast cancer, it has been suggested that the over expression of p53 protein in the nucleus is an indicator of poor prognosis, which must be borne in mind in selecting coadjuvant treatment for each patient [14].

In our study we found a positive p53 expression in high histologic grading is $48.0 \%$ among 50 cases and a negative p53 expression in 16 cases $(32.0 \%)$ where in statistical analysis there is no correlation between a high expression of p53 and higher histologic grading of tumor $(P=0.089)$.

Sirvent, Salvado et al. study about IHC analysis of p53 expression in 153 cases of breast cancer, correlating with histological grade, axillary node status, hormone receptors, cell proliferation fraction and expression of the c-erB-2 oncoprotein. Of all the breast cancer tissue analyzed, 43.97\% were positive $\mathrm{p} 53$, over expression of this protein show direct statistically significant relationship to histological grade, cell proliferation faction and c-erB-2, but had no statistically significant relationship with axillary node status.

Mutation and the over expression of p53 protein are directly related to histological grade [14].

GATA-3 is a nuclear of GATA-3 transcriptions regulatory family and is important in directing cell fate. Development and or differentiation in a member of cell types including luminal epithelial cells of mammary gland. GATA-3 is a member of the GATA-3 transcription regulatory family and is important in directing cell fate, development, and or differentiation in a number of cell types including luminal epithelial cells of the mammary gland. Although we and others have shown that GATA-3 levels were generally higher in malignant cells compared with morphologically normal epithelium, within malignant tissue, relatively lower levels of GATA-3 portended a poorer outcome compared with relatively higher expression. Consistent with the role of GATA-3 in the development and differentiation of normal mammary epithelium, we further observed that lower levels of GATA-3 were generally associated with a higher-grade, less differentiated malignancy [4].

In this study, we used a IHC to reassess associations of GATA-3 expression with Histopathologic grading of 50 samples of breast cancer in Makassar. We found that positive expression of GATA-3 had amount of 28 samples (28\%) among high histopathologic grading of breast cancer. Even though the higher expression positive GATA-3 seen in high histopathologic grading but there is no statistically 
significant correlation between them. Negative (low) expression GATA-3 only had 12 samples among high level of histologic grading $(20 \%)$ of the result.

Mehra et al. found low GATA-3 expression was associated with higher histologic grade $(P<0.001)$, positive nodes $(P=$ $0.002)$, larger tumor size $(P=0.03)$, negative estrogen receptor and progesterone receptor $(P<0.001$ for both) [5].

$\mathrm{Ki}-67$ protein (also known as MKI67) is a cellular marker for proliferation. This nuclear protein is expressed in proliferating cells during G1 through $\mathrm{M}$ phases of the cell cycle, but is not detected in resting cells. The Ki-67 expression as detected by immunohistochemistry is one of the most reliable indicators of the proliferative status of cancer cells and is referred to as $\mathrm{Ki}-67$ henceforward. In 2009, at the St-Gallen breast cancer conference, Ki-67 was recommended as a biomarker for prognosis and sensitivity of cancer cells to endocrine therapy or chemotherapy. In 2011, $\mathrm{Ki}-67$ was regarded as one of the factors influencing molecular subtypes. Ki-67 expression is closely associated with the growth and invasion of breast cancer: $\mathrm{Ki}-67$ positive breast cancers are more active in growth, more aggressive in invasion, and more metastatic [3, 7].

In conclusion, we found there is no correlation between higher expression of p53 and low expression of GATA-3 with higher histopathology grading of breast cancer. High expression of Ki-67 have significantly statistic analysis with high expression of histopathology grading of mammary cancer.

\section{References}

[1] American Cancer Society. 2009-2010. Breast Cancer Facts and Figures.

[2] Tjindarbumi, D., Mangunkusumo, R. 2002. Cancer In Indonesia, Present and Future. Jpn J Clin Onco. (Suplement 1) S17-S21.

[3] Li, F. Y., Wu, S. G., Zhou, J., et al. 2014. Prognostic Value of Ki-67 in Breast Cancer Patients with Positive Axillary Lymph Nodes: A Retrospective Cohort Study. Open One. 9: 2.

[4] Yoon, B. S. N. K., Maresh, B. S. E. L., et al. 2010. Higher
Levels of GATA-3 Predict Better Survival in Women with Breast Cancer. Human Pathology. 41: 1794-1801.

[5] Mehra, R., Varambally, S., et al. 2005. Identification of GATA-3 as a Breast Cancer Prognostic Marker by Global Gene Expression Meta-analysis. Cancer Res. 65: 1125911264.

[6] Liu, D. P., Song, H., Xu, Y., et al. 2010. A Common Gain of Function of p53 Cancer Mutants in Inducing Genetic Instability. Oncogene. 29: 949-956.

[7] Cheang, M. C., Chia, S. K., Voduc, D., Gao, D., Leung, S., et al. 2009. Ki-67 Index, HER2 Status, and Prognosis With Luminal B Breast Cancer. Journal of the National Cancer Institute. 101: 736-750.

[8] Scholzen, T., Gerdes, J. 2000. The Ki-67 Protein: From the Known and The Unknown. Journal of Cellular Physiology. 182: $311-322$

[9] Goldhirsch, A., Ingle, J. N., Gelbert, R. D., Thurlimann, B., et al. 2009. Thresholds for Therapies: Highlights of the St Gallen International Expert Consensus on the Primary Therapy of Early Breast Cancer 2009. Annals of Oncology. 20: 13191329.

[10] Nishimura, R., Osaka, T. 2010. Clinical Significance of Ki-67 in Neoadjuvant Chemotherapy for Primary Breast Cancer as a Predictor for Chemo sensitivity and for Prognosis. Department of Breast and Endocrine Surgery, Kumamoto City Hospital, Kumamoto, Japan: Japanese Breast Cancer. 17: 269275 .

[11] Weisner, G. F., Magener, A. 2009. Ki-67 as a Prognostic Molecular Marker in Routine Clinical use in Breast Cancer Patients. The Breast. 18: 135-141.

[12] Dydensborg, A. B., Rose, A. A. N., et. al. 2009. GATA-3 Inhibits Breast Cancer Growth and Pulmonary Breast Cancer Metastasis. Oncogene.28: 2634-2642.

[13] Albergaria, A., Joana, P., et al. 2009. Expression of Foxal and GATA-3 in Breast Cancer. The Prognostic Significance in Hormone Receptor-Negative Tumors.

[14] Sirvent, J. J., Salvado, M. T., et al. 1995. p53 in Breast Cancer. Its Relation to Histological Grade, Lymph-node Status, Hormon Receptors, Cell-Proliferation fraction (Ki-67) and c-erB-2. Immunohistochemical study of 153 Cases. Histopathol.10: 531-539. 